\title{
KAJIAN BATAS PENGARUH KOTA TERHADAP WILAYAH SEKITARNYA (STUDI KASUS: KOTA MANADO, KOTA BITUNG, KOTA TOMOHON, DAN KOTA KOTAMOBAGU)
}

\author{
Anna Maria Watung Supit \\ O. Esry H. Laoh \\ Melissa L. G. Tarore
}

\begin{abstract}
This study aims to find out how far the limits of city influence on the surrounding area (case study: Manado City, Bitung City, Tomohon City, and Kotamobagu City). The data used in this research is secondary data. The variables measured in this study include population (soul) and distance ( $\mathrm{km}$ ). In this research the analysis used is Breaking Point. The study took place from October to April starting from preparation, data collection, to the production of research results. The location of the research was conducted in Manado City. The results showed that the development of City Region (BWK) of Manado City, Bitung, Tomohon, and Kotamobagu, has different influence limits. BWK Manado City Center has a stronger boundary of influence over Airmadidi, Tondano Utara, Bitung and Amurang areas. BWK Bitung City Center has stronger limits of influence, especially on Kauditan and Airmadidi areas. While the area of Manado has lower influence limits. The limits of influence of BWK Tomohon City Center have a stronger boundary effect on North Tondano and Sonder areas. While the area of Manado has lower influence limits. Similarly, the Influence Limits of BWK Kotamobagu City Center has a stronger influence limit on the Amurang and Tutuyan areas. Then the relationship of the four cities shows that Manado City has more influence than Bitung, Tomohon and Kotamobagu.
\end{abstract}

Keywords: limits of city influence, Manado City, Bitung City, Tomohon City, Kotamobagu City.

\begin{abstract}
ABSTRAK
Penelitian ini bertujuan untuk mengetahui berapa jauh batas pengaruh kota terhadap wilayah sekitarnya (studi kasus : Kota Manado, Kota Bitung, Kota Tomohon, dan Kota Kotamobagu). Data yang digunakan dalam penelitian ini adalah data sekunder. Variabel-variabel yang diukur dalam penelitian ini mencakup jumlah penduduk (jiwa) dan jarak $(\mathrm{km})$. Dalam penelitian ini analisis yang digunakan ialah Breaking Point. Penelitian ini berlangsung dari bulan Oktober hingga bulan April mulai dari persiapan, pengumpulan data, sampai dengan pembuatan hasil penelitian. Lokasi penelitian dilakukan di Kota Manado. Hasil penelitian menunjukkan bahwa pengembangan Bagian Wilayah Kota (BWK) Kota Manado, Bitung, Tomohon, dan Kotamobagu, memiliki batas pengaruh yang berbeda-beda. BWK Pusat Kota Manado memiliki batas pengaruh yang lebih kuat terhadap wilayah Airmadidi, Tondano Utara, Bitung, dan Amurang. BWK Pusat Kota Bitung memiliki batas pengaruh lebih kuat khususnya terhadap wilayah Kauditan dan Airmadidi. Sedangkan terhadap wilayah Manado memiliki batas pengaruh lebih rendah. Batas pengaruh BWK Pusat Kota Tomohon memiliki batas pengaruh lebih kuat terhadap wilayah Tondano Utara dan Sonder. Sedangkan terhadap wilayah Manado memiliki batas pengaruh lebih rendah. Demikian juga Batas Pengaruh BWK Pusat Kota Kotamobagu memiliki batas pengaruh lebih kuat terhadap wilayah Amurang dan Tutuyan. Kemudian hubungan dari keempat kota-kota tersebut menunjukkan bahwa kota Manado memiliki pengaruh lebih besar dari kota Bitung, Tomohon dan Kotamobagu.
\end{abstract}

Kata kunci: batas pengaruh kota, Kota Manado, Kota Bitung, Kota Tomohon, Kota Kotamobagu. 


\section{PENDAHULUAN}

\section{Latar Belakang}

Pembangunan merupakan suatu usaha atau rangkaian usaha pertumbuhan dan perubahan yang berencana dan dilakukan secara sadar oleh suatu bangsa, negara dan pemerintah, menuju modernitas dalam rangka pembinaan bangsa (Siagian, 2009). Wilayah sebagai unit geografis dengan batas-batas spesifik tertentu di mana komponen-komponen wilayah tersebut satu sama lain saling berinteraksi secara fungsional (Rustiadi, et al, 2009).

Kota merupakan pusat kegiatan masyarakat daerah sekitarnya. Hal ini karena terdapat pusatpusat kegiatan yang melibatkan masyarakat daerah sekitar untuk melakukan suatu kegiatan. Suatu kota berkembang berdasarkan pada potensi yang dimiliki oleh kota tersebut. Oleh karena itu, kota menjadi pusat perkembangan bagi daerahdaerah sekitarnya (Gunawan dkk, 2007). Suatu kota yang besar, selain memiliki daerah belakang yang berupa daerah pertanian, juga memiliki beberapa kota kecil. Apabila kota kecil banyak tergantung dari kota besar, maka kota kecil termasuk dalam daerah pengaruh dari kota yang lebih besar.

Kota Manado merupakan Ibukota Provnsi Sulawesi Utara yang menjadi pusat kegiatan masyarakat pada umumnya yang menyediakan sarana dan prasarana untuk kebutuhan masyarakat. Kota Bitung sebagai kota industry yang cukup besar membuat Kota Bitung mempunyai keunggulan khususnya di industry perikanan. Kota Kotamobagu adalah salah satu Kota di Provinsi Sulawesi Utara yang memiliki tujuan untuk memberikan pelayanan dan memobilisasi pembangunan bagi masyarakat sekitar Kota agar terciptanya kesejahteraan dan kemakmuran rakyat. Sedangkan Kota Tomohon, adalah Kota yang memiliki keunggulan di bidang pariwisata karena Kota Tomohon di kenal sebagai Kota Bunga. Oleh sebab itu, berkaitan dengan hal ini peneliti ingin mengkaji bagaimana dan berapa jauh batas pengaruh kota terhadap wilayah sekitarnya (studi kasus : Kota Manado, Kota Bitung, Kota Kotamobagu, dan Kota Tomohon). Hal ini karena kota-kota tersebut sudah berkembang dan telah menjadi pusat pertumbuhan dan pengembangan.

\section{Perumusan Masalah}

Berdasarkan latar belakang di atas maka dapat dirumuskan berapa jauh batas pengaruh kota terhadap wilayah sekitarnya (studi kasus : Kota Manado, Kota Bitung, Kota Tomohon, dan Kota Kotamobagu).

\section{Tujuan Penelitian}

Tujuan penelitian ini untuk mengetahui berapa jauh batas pengaruh kota terhadap wilayah sekitarnya (studi kasus : Kota Manado, Kota Bitung, Kota Tomohon, dan Kota Kotamobagu).

\section{Manfaat Penelitian}

Penulisan makalah ini bermanfaat agar dapat menambah wawasan pengetahuan bagi pembaca, serta dapat memberikan informasi tentang kajian batas pengaruh kota terhadap wilayah sekitarnya (studi kasus : Kota Manado, Kota Bitung, Kota Tomohon, dan Kota Kotamobagu).

\section{METODOLOGI PENELITIAN}

\section{Waktu dan Tempat Penelitian}

Penelitian ini dilaksanakan selama tiga bulan dari bulan Oktober sampai bulan April dan berlokasi di Kota Manado.

\section{Jenis Data}

Penelitian ini menggunakan data sekunder. Data sekunder dikumpulkan dan diperoleh dari lembaga/instansi sebagai berikut:

1. Kantor Badan Pusat Statistika Provinsi Sulawesi Utara.

2. Menggunakan alat ukur Global Positioning System (GPS).

\section{Konsepsi Pengukuran Variabel}

Adapun variabel-variabel yang di ukur dalam penelitian ini mencakup :

1. Jumlah penduduk = Jumlah seluruh seluruh penduduk yang hidup dan tinggal dalam wilayah yang diteliti (jiwa). 
2. Jarak = Jauh Letak antara suatu wilayah dengan wilayah lain diteliti (kilometer). Dalam penelitian ini, jarak di ukur dari Wilayah Kota Manado, Kota Bitung, Kota Kotamobagu, dan Kota Tomohon dan titik terluar dari setiap wilayah yang diteliti.

\section{Metode Analisis Data}

Untuk menganalisa batas pengaruh kota terhadap wilayah sekitarnya (studi kasus : Kota Manado, Kota Bitung, Kota Kotamobagu, dan Kota Tomohon) dengan menggunakan theory breking point menurut Harsthorn dan Alexander (1988).

$$
\mathrm{BP}=\frac{d}{1+\sqrt{\text { Pend.X/Pend.Y }}}
$$

$$
\begin{aligned}
\mathrm{BP}= & \text { Batas Pengaruh (Breaking Point) } \\
& \text { Kota/Desa X Dan Kota/Desa Y } \\
\mathrm{d} \quad= & \text { Jarak Antara Kota/Desa X Dan } \\
& \text { Kota/Desa Y }
\end{aligned}
$$

Pend. $X=$ Jumlah Penduduk Kota/DesaX Pend. Y= Jumlah Penduduk Kota/Desa Y

\section{HASIL DAN PEMBAHASAN}

\section{Gambaran Umum Provinsi Sulawesi Utara}

\section{Letak Wilayah}

Sulawesi Utara merupakan Provinsi yang beribukotakan Manado, mempunyai 15 Kabupaten/Kota yakni Kabupaten Bolaang Mongondow, Kabupaten Bolaang Mongondow Selatan, Kabupaten Bolaang Mongondow Timur, Kabupaten Bolaang Mongondow Utara, Kabupaten Minahasa, Kabupaten Minahasa Selatan, Kabupaten Minahasa Tenggara, Kabupaten Minahasa Utara, Kota Bitung, Kota Manado, Kota Kotamobagu, dan Kota Tomohon.

\section{Batas Pengaruh Bagian Wilayah Kota (BWK) Kota Terhadap Wilayah Sekitarnya \\ Pada penelitian ini telah dianalisis batas pengaruh Bagian Wilayah Kota(BWK) Kota Manado terhadap Airmadidi, Tondano Utara, Amurang dan Bitung. Batas pengaruh Bagian Wilayah Kota (BWK) Kota Bitung terhadap}

Kauditan, Airmadidi dan Manado. Batas pengaruh Bagian Wilayah Kota (BWK) Kota Tomohon terhadap Tondano Utara, Sonder, dan Manado. Batas pengaruh Bagian Wilayah Kota (BWK) Kota Kotamobagu terhadap Amurang dan Tutuyan. Dianalisis menggunakan theory breaking point dengan menggunakan formula yang telah di tetapkan sebelumnya. Jarak geografis merupakan bagian dari variable yang dibutuhkan dalam analisis yang di maksud.

Tabel 1. Jarak Bagian Wilayah Kota (BWK) Kota Manado Terhadap Wilayah Sekitarnya

\begin{tabular}{lc}
\hline \multicolumn{1}{c}{ Wilayah } & Jarak $(\mathrm{Km})$ \\
\hline Manado-Airmadidi & 20.3 \\
Manado-Tondano & 31.26 \\
Manado-Bitung & 41 \\
Manado-Amurang & 53.1 \\
\hline
\end{tabular}

Tabel 2. Jarak Bagian Wilayah Kota (BWK) Kota Bitung Terhadap Wilayah Sekitarnya

\begin{tabular}{lc}
\hline \multicolumn{1}{c}{ Wilayah } & Jarak $(\mathrm{Km})$ \\
\hline Bitung-Kauditan & 12 \\
Bitung-Airmadidi & 18.6 \\
Bitung-Manado & 41 \\
\hline
\end{tabular}

Tabel 3. Jarak Bagian Wilayah Kota (BWK) Kota Tomohon Terhadap Wilayah Sekitarnya

\begin{tabular}{lc}
\hline \multicolumn{1}{c}{ Wilayah } & Jarak $(\mathrm{Km})$ \\
\hline Tomohon-Tondano Utara & 14.9 \\
Tomohon-Sonder & 15.4 \\
Tomohon-Manado & 27.7 \\
\hline
\end{tabular}

Tabel 4. Jarak Bagian Wilayah Kota (BWK) Kota Kotamobagu Terhadap Wilayah Sekitarnya

\begin{tabular}{lc}
\hline \multicolumn{1}{c}{ Wilayah } & Jarak $(\mathrm{Km})$ \\
\hline Kotamobagu-Amurang & 132 \\
Kotamobagu-Tutuyan & 49.5 \\
\hline
\end{tabular}

Tabel 5. Jumlah Penduduk Bagian Wilayah Kota (BWK) Kota Terhadap Wilayah Sekitarnya

\begin{tabular}{lc}
\hline \multicolumn{1}{c}{ Wilayah } & Jumlah Penduduk (Jiwa) \\
\hline Kota Manado & 427906 \\
Kota Bitung & 208995 \\
Kota Tomohon & 101981 \\
Kota Kotamobagu & 121699 \\
Tondano & 69622 \\
Airmadidi & 28833 \\
Amurang & 18158 \\
Kauditan & 24467 \\
Sonder & 18370 \\
Tutuyan & 12179 \\
\hline
\end{tabular}

Sumber : Data BPS Tahun 2016 
Batas Pengaruh Bagian Wilayah Kota (BWK) Kota Manado Terhadap Wilayah Sekitarnya

Kota Manado Terhadap Airmadidi

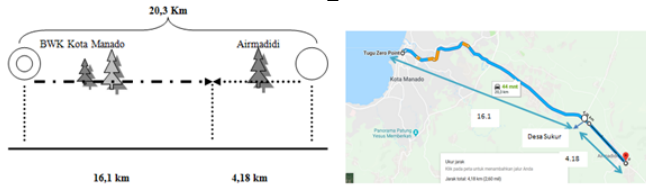

Kota Manado memiliki pengaruh lebih kuat daripada BWK Airmadidi yang berada pada jarak $16.1 \mathrm{Km}$. Titik batas pengaruh berada di wilayah Sukur

\section{Kota Manado Terhadap Tondano}
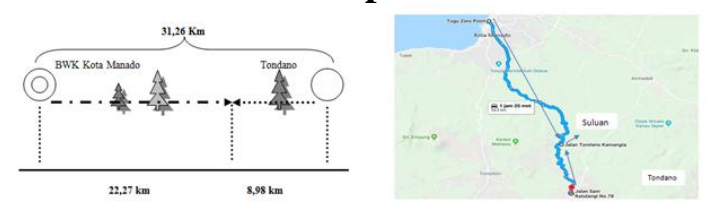

Kota Manado memiliki pengaruh lebih kuat daripada wilayah Tondano berada pada jarak $30.7 \mathrm{~km}$. Titik batas pengaruh berada di Suluan.

Kota Manado Terhadap Bitung

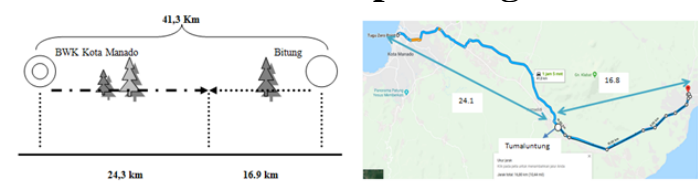

Batas pengaruh BWK Kota Manado lebih kuat dari wilayah Bitung berada pada jarak $24.1 \mathrm{~km}$. Titik batas pengaruh berada di Tumaluntung, Airmadidi.

\section{Kota Manado Terhadap Amurang}
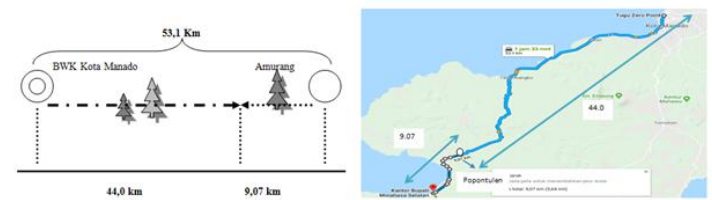

Batas pengaruh BWK Kota Manado lebih kuat daripada wilayah Amurang berada pada titik $44.0 \mathrm{~km}$. Titik batas pengaruh berada di Popontulen, Amurang.

Batas Pengaruh Bagian Wilayah Kota (BWK) Kota Bitung Terhadap Wilayah Sekitarnya

Kota Bitung Terhadap Kauditan

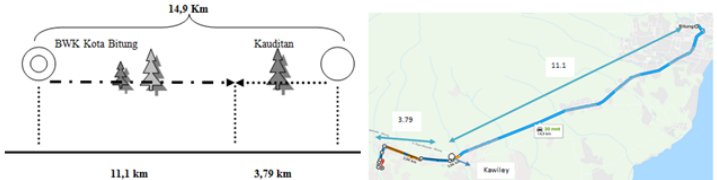

Batas pengaruh BWK Kota Bitung lebih kuat daripada wilayah Kauditan yang berada pada jarak $11.1 \mathrm{~km}$. Titik batas pengaruh berada di Kawiley, Kauditan.

\section{Kota Bitung Terhadap Airmadidi}

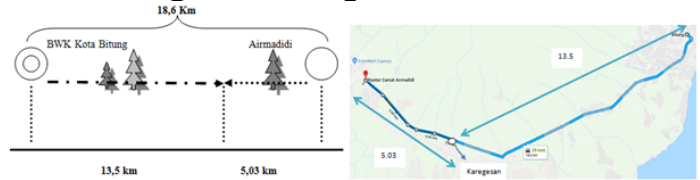

Batas pengaruh BWK Kota Bitung lebih kuat daripada wilayah Airmadidi yang berada pada jarak $13.5 \mathrm{~km}$. Titik batas pengaruh berada di Karegesan, Kauditan.
Kota Bitung Terhadap Manado

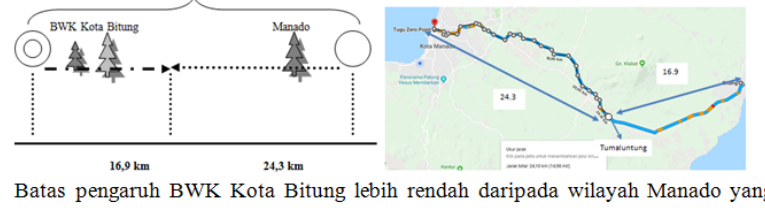

Batas pengaruh BWK Kota Bitung lebih rendah daripada wilayah Manado yang berada pada jarak $16.9 \mathrm{~km}$. Titik batas pengaruh berada di Desa Tumaluntung.

Batas Pengaruh Bagian Wilayah Kota (BWK) Kota Tomohon Terhadap Wilayah Sekitarnya

Kota Tomohon Terhadap Tondano

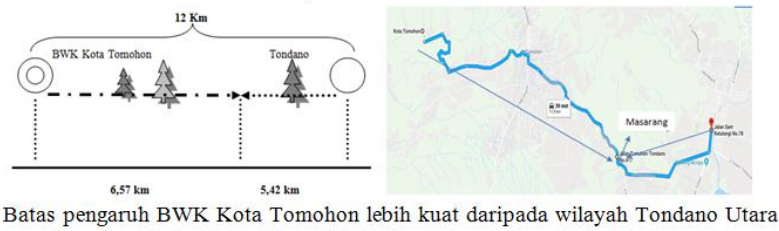
yang berada pada jarak $10.9 \mathrm{~km}$. Titik batas pengaruh berada di Masarang.

Kota Tomohon Terhadap Sonder
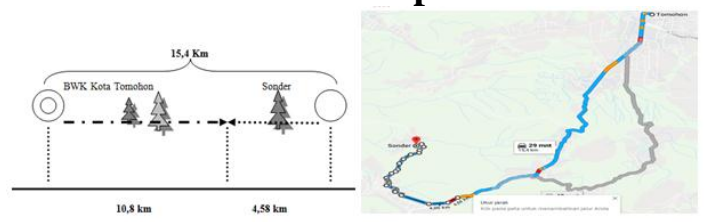

Batas pengaruh BWK Kota Tomohon lebih kuat daripada Wilayah Sonder berada pada jarak $10.8 \mathrm{Km}$. Titik batas pengaruh masih berada di wilayah Sonder.

Kota Tomohon Terhadap Manado

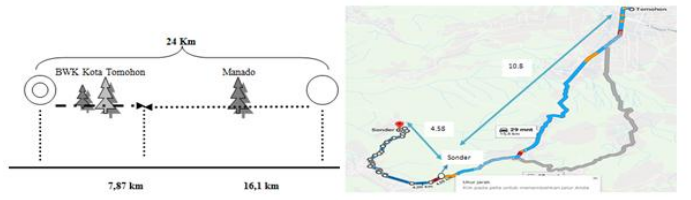

Batas pengaruh BWK Kota Tomohon lebih lemah daripada Wilayah Manado karena berada pada jarak $16.1 \mathrm{Km}$. Titik batas pengaruh berada di wilayah Tinoor.

Batas Pengaruh Bagian Wilayah Kota (BWK) Kota Kotamobagu Terhadap Wilayah Sekitarnya

Kota Kotamobagu Terhadap Amurang

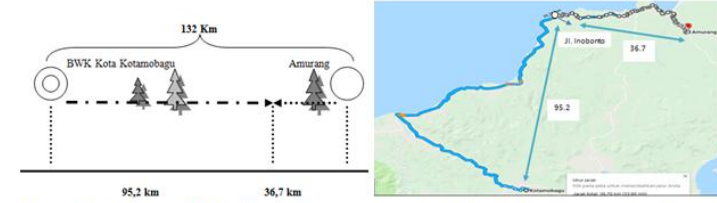

Batas pengaruh BWK Kota Kotamobagu lebih kuat daripada wilayah Amurang karena berada pada jarak $95.2 \mathrm{Km}$. Titik batas pengaruh berada di Jl Inobonto.

\section{Kota Kotamobagu Terhadap Tutuyan}

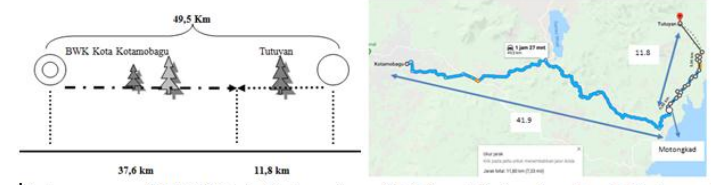

Batas pengaruh BWK Kota Kotamobagu lebih kuat daripada wilayah Tutuyan berada pada jarak $41.9 \mathrm{Km}$. Titik batas pengaruh berada di Motongkad, Nuangan, Bolaang Mongondow Timur. 


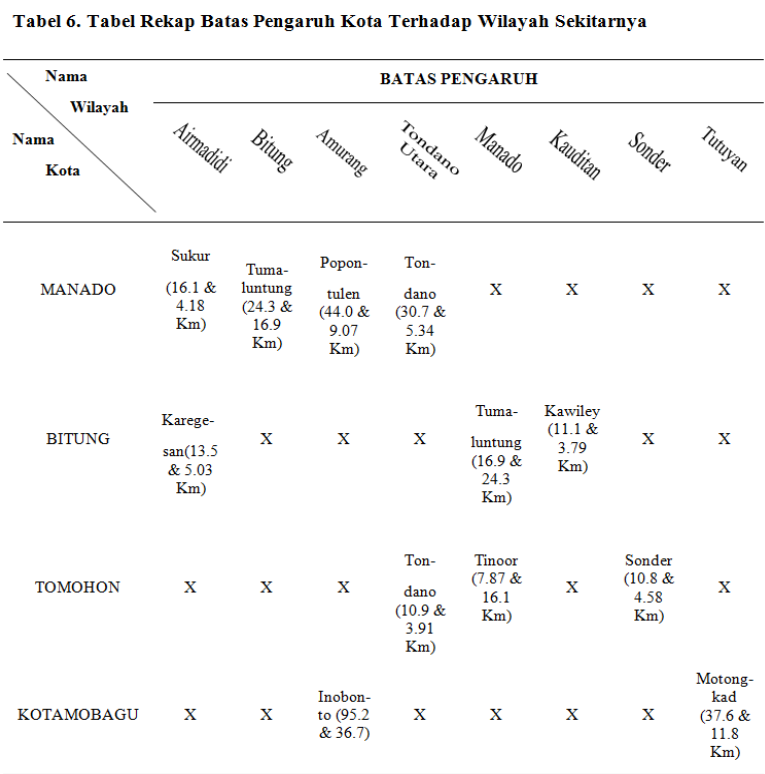

Tabel 6 rekap di atas menjelaskan bahwa Kota Manado, Kota Bitung, Kota Tomohon, dan Kota Kotamobagu dengan wilayah pengaruhnya memiliki hubungan subordinat dimana hubungan ini menunjukkan bahwa wilayah tersebut masih bergantung pada kota orde yang lebih tinggi tempatnya berhubungan.

\begin{tabular}{|c|c|c|c|c|}
\hline \multirow{2}{*}{$\begin{array}{l}\text { NAMA } \\
\text { KOTA }\end{array}$} & \multicolumn{4}{|c|}{ BATAS PENGARUH } \\
\hline & MANADO & BITUNG & томоноN & KOTAMOBAGU \\
\hline MANADO & $\mathrm{x}$ & $\begin{array}{l}\text { Tumaluntung } \\
(24.3 \& 16.9 \\
\mathrm{Km})\end{array}$ & $\begin{array}{l}\text { Tinoor }(16.1 \\
\& 7.87 \mathrm{Km})\end{array}$ & $\begin{array}{c}\text { Nonapan } 2 \\
(119.8 \& 63.8 \\
\mathrm{Km})\end{array}$ \\
\hline BITUNG & $\begin{array}{c}\text { Tuma- } \\
\text { luntung }(16.9 \\
\& 24.3 \mathrm{Km})\end{array}$ & $\mathrm{x}$ & $\begin{array}{c}\text { Tanggari }(29.4 \\
\& 20.5 \mathrm{Km})\end{array}$ & $\begin{array}{c}\text { Tenga }(125.9 \& \\
96.0 \mathrm{Km})\end{array}$ \\
\hline TOMOHON & $\begin{array}{l}\text { Tinoor }(7.87 \\
\& 16.1 \mathrm{Km})\end{array}$ & $\begin{array}{l}\text { Tanggari }(20.5 \\
\& 29.4 \mathrm{Km})\end{array}$ & $\mathrm{x}$ & $\begin{array}{c}\text { Blonko, } \\
\text { Sinonsayang } \\
(82.6 \& 90.3 \\
\mathrm{Km})\end{array}$ \\
\hline KOTAMOBAGU & $\begin{array}{c}\text { Nonapan } 2 \\
(63.8 \& 119.8 \\
\mathrm{Km})\end{array}$ & $\begin{array}{l}\text { Tenga }(96.0 \& \& \\
125.9 \mathrm{Km})\end{array}$ & $\begin{array}{c}\text { Blonko, } \\
\text { Sinonsayang } \\
(90.3 \& 82.6 \\
\mathrm{Km})\end{array}$ & $\mathrm{x}$ \\
\hline
\end{tabular}

Tabel 7 di atas menjelaskan bahwa empat kota-kota besar tersebut memiliki hubungan dan batas pengaruh yang berbeda-beda. BWK Kota Manado memiliki pengaruh lebih kuat dari pada Kota Bitung. BWK Kota Bitung memiliki pengaruh lebih kuat terhadap Kota Tomohon. BWK Kota Tomohon memiliki pengaruh lebih rendah tehadap Kota Manado. Sedangkan Kota Kotamobagu memiliki pengaruh lebih rendah terhadap Kota Manado.
Tabel 8. Jumlah Penduduk Bagian Wilayah Kota (BWK) Kota Terhadap Wilayah Sekitarnya Tahun 2011

\begin{tabular}{lc}
\hline \multicolumn{1}{c}{ Kota } & Jumlah Penduduk (Jiwa) \\
\hline Manado & 415.114 \\
Bitung & 187.652 \\
Tomohon & 92.583 \\
Kotamobagu & 108.891 \\
\hline
\end{tabular}

Tabel 8 di atas menjelaskan jumlah penduduk tahun 2011, dan di ilustrasikan dalam tabel rekap di bawah ini :

\begin{tabular}{|c|c|c|c|c|}
\hline \multirow{2}{*}{$\begin{array}{l}\text { NAMA } \\
\text { KOTA }\end{array}$} & \multicolumn{4}{|c|}{ BATAS PENGARUH } \\
\hline & MANADO & BITUNG & TомоноN & КОТАМОВАGU \\
\hline MANADO & $\mathrm{x}$ & $\begin{array}{l}\text { Tumaluntung } \\
(24.7 \mathrm{Km} \& \\
16.6 \mathrm{Km})\end{array}$ & $\begin{array}{l}\text { Tinoor (16.3 } \\
\mathrm{Km} \& 7.69 \\
\mathrm{Km})\end{array}$ & $\begin{array}{c}\text { Nonapan } \\
(119.8 \mathrm{Km} \& \\
63.8 \mathrm{Km})\end{array}$ \\
\hline BITUNG & $\begin{array}{c}\text { Tumaluntung } \\
(16.6 \mathrm{Km} \& \\
24.7 \mathrm{Km})\end{array}$ & $\mathrm{x}$ & $\begin{array}{c}\text { Tanggari }(29.3 \\
\& 20.6 \mathrm{Km})\end{array}$ & $\begin{array}{c}\text { Tenga }(125.9 \& \\
95.9 \mathrm{Km})\end{array}$ \\
\hline томоноN & $\begin{array}{c}\text { Tinoor }(7.69 \& \\
16.3 \mathrm{Km})\end{array}$ & $\begin{array}{l}\text { Tanggari }(20.6 \\
\& 29 \mathrm{Km})\end{array}$ & $\mathrm{x}$ & $\begin{array}{l}\text { Sinonsayang } \\
(89.9 \& 82.9 \\
\mathrm{Km})\end{array}$ \\
\hline $\begin{array}{c}\text { КОтА } \\
\text { MOBAGU }\end{array}$ & $\begin{array}{l}\text { Nonapan } \\
(63.8 \mathrm{Km} \& \\
119.8 \mathrm{Km})\end{array}$ & $\begin{array}{c}\text { Tenga }(95.9 \& \\
125.9 \mathrm{Km})\end{array}$ & $\begin{array}{l}\text { Sinonsayang } \\
(82.9 \& 89.9 \\
\mathrm{Km})\end{array}$ & $\mathrm{x}$ \\
\hline
\end{tabular}

Tabel 9 di atas menjelaskan bahwa empat kota-kota besar tersebut memiliki hubungan dan batas pengaruh yang berbeda-beda. Dari hasil perhitungan rekap untuk tahun 2011 di dapatkan bahwa perubahan batas pengaruh kota tidaklah terjadi perubahan drastic dengan batas pengaruh kota untuk tahun 2016. Hal ini di karenakan jarak antara kota untuk tahun 2011 dan 2016 tidaklah jauh berbeda. Kemudian perubahan jumlah penduduk yang terjadi tidak terlalu signifikan.

\section{KESIMPULAN DAN SARAN}

\section{Kesimpulan}

Pengembangan Bagian Wilayah Kota (BWK) mempengaruhi pada wilayah sekitarnya yaitu Manado, Bitung, Tomohon, dan Kotamobagu, memiliki batas pengaruh yang berbeda-beda. BWK Pusat Kota Manado memiliki batas pengaruh yang lebih kuat terhadap wilayah Airmadidi yang berada pada jarak 16.1 Km, wilayah Tondano $22.27 \mathrm{Km}$, wilayah Bitung 24.1 Km, dan wilayah Amurang $44.0 \mathrm{Km}$. 
BWK Pusat Kota Bitung memiliki batas pengaruh lebih kuat khususnya terhadap wilayah Kauditan yang berada pada jarak 11.1 $\mathrm{Km}$ dan wilayah Airmadidi $13.5 \mathrm{Km}$. Sedangkan batas pengaruh BWK Pusat Kota Bitung terhadap wilayah Manado memiliki batas pengaruh lebih rendah yang berada pada jarak $16.8 \mathrm{Km}$. Hal tersebut karena wilayah Manado memiliki sarana prasarana yang lebih memadai daripada wilayah Kota Bitung yang membuat sebagian masyarakat lebih melakukan kegiatan di wilayah Manado.

Batas pengaruh BWK Pusat Kota Tomohon memiliki batas pengaruh lebih kuat terhadap wilayah Tondano yang berada pada jarak $6.57 \mathrm{Km}$ dan Sonder 10.8 Km. Sedangkan batas pengaruh BWK Pusat Kota Tomohon terhadap wilayah Manado memiliki batas pengaruh lebih rendah karena berada pada jarak $9.08 \mathrm{Km}$. Demikian juga Batas Pengaruh (BWK) Pusat kota Kotamobagu memiliki batas pengaruh lebih kuat terhadap wilayah Amurang yang berada pada jarak $95.2 \mathrm{Km}$ dan wilayah Tutuyan $37.6 \mathrm{Km}$. Sedangkan hubungan batas pengaruh BWK Kota Manado terhadap Kota Bitung, Kota Tomohon, dan Kota Kotamobagu memiliki pengaruh yang lebih kuat.

\section{Saran}

Pengembangan wilayah sekitar Kota khususya BWK Pusat Kota Manado, BWK Pusat Kota Bitung, BWK Pusat Kota Tomohon, dan BWK Pusat Kota Kotamobagu, dapat menjadi perhatian bagi wilayah pengaruh sekitarnya agar wilayah-wilayah tersebut dapat mengalami perubahan pengembangan wilayah yang lebih baik dan dapat menyediakan fasilitas sarana dan prasarana yang lebih baik bagi masyarakat sekitar wilayah tersebut, dilihat dari pusat-pusat perdagangan, industri, system transportasi, pendidikan, fasilitas kesehatan, dsb.

\section{DAFTAR PUSTAKA}

Adisasmita, Rahardjo. 2008. Pengembangan Wilayah (Konsep dan Teori). Graha Ilmu. Jogyakarta.
Gunawan T, Sukwardjono, M Sukoco, A Sudarsomo, Dan Soewadi. 2007. Geografi. Inter Plus. Jakarta.

Hartshorn, T. A. And J. W. Alexander. 1988. Economic Geografi. Prentise Hall. New Jersey.

Hobbs, F.D, 1995, Perencanaan Dan Teknik Lalu Lintas, Penerbit Gadjah Mada University Press. Yogyakarta.

Irawan M. Suparmoko. 2002. Ekonomika Pembangunan, Edisi ke 6. BPFE. Yogyakarta.

Kabupung S. F. 2012. Studi Citra Kota Maumere Di Nusa Tenggara Timur. Jurnal S2 Thesis Universitas Atma Jaya. Yogyakarta.

Khosim A. 2006. Geografi.Grasindo. Jakarta.

Rustiadi, S. Saefulhakim, dan D. R. Panuju. 2009. Perencanaan dan pengembangan wilayah. Crestpent Press dan Yayasan Obor Indonesia. Jakarta.

Sirojuzilam dan K. Mahalli. 2010. Regional: Pembangunan, Perencanaan dan Ekonomi. Sumatera Utara University Press. Medan.

Siagian, P. Sondang. 2009. Pembangunan. Penerbit Gunung Agung. Gadjah Mada University Press. Yogyakarta.

Surakanti, S. Wardono. 2015. Tesis Pascasarjana; Analisis Sistem Jaringan Transportasi Dan Model Gravitasi Di Kota Ambon. Penerbit Universitas Sam Ratulangi. Manado.

Tarigan, R. 2005. Perencanaan Pembangunan Wilayah. PT. Bumi Aksara. Jakarta.

Tarigan, R. 2013. Ekonomi Regional Teori Dan Aplikasi. Pt Bumi Aksara. Jakarta.

Todaro, 2003. Pembangunan Ekonomi. Erlangga. Jakarta. 